\title{
INDEKS KEPUASAN KELUARGA PASIEN TERHADAP PELAYANAN RUMAH SAKIT BUDI KEMULIAAN BATAM
}

\author{
Rizki Eka Putra \\ Dosen Tetap Prodi Akuntasi Fakultas Ekonomi Universitas Riau \\ Kepulauan
}

\begin{abstract}
Abstrak
Rumah Sakit Budi Kemuliaan Batam merupakan salah satu rumah sakit terbesar di Batam yang berperan utama didalam meningkatkan tingkat kesehatan masyarakat. Rumah Sakit Budi Kemuliaan Batam (RSBK) Batam mengemban tugas dan tanggung jawab yang sangat berat, disamping mengemban tugas peningkatan kesehatan masyarakat berdasarkan undang-undang kesehatan, Rumah Sakit Budi Kemuliaan Batam juga dituntut untuk memberikan pelayanan yang terbaik kepada masyarakat, murah dan nyaman, sehingga memberikan kepuasan masyarakat. Rumusan Masalah dari penelirtian ini adalah berapa indeks kepuasan keluarga pasien terhadap kualitas pelayanan Rumah Sakit Budi Kemuliaan Batam. Untuk melihat seberapa besar kepuasan keluarhga pasien terhadap pelayan kulaitas pelayanan maka prinsip pelayanan sebagaimana telah ditetapkan dalam Keputusan Men.PAN Nomor : 63/KEP/M.PAN/7/2003, yang kemudian dikembangkan menjadi 14 unsur yang "relevan, valid" dan "reliabel", sebagai unsur minimal yang harus ada untuk dasar pengukuran indeks kepuasan masyarakat. Sebuah jasa akan berkaitan sekali dengan pelayanan. Jika sebuah pelayanan bagus maka identik dengan hasil jasanya yang bagus, meskipun belum tentu pelayanan bagus jasa yang dihasilkan pasti bagus. Pelayanan prima merupakan suatu layanan yang diberikan kepada publik yang mampu memuaskan pihak yang dilayani, hal tersebut sebagaimana disebutkan dalam SK Menpan No. 81 Tahun 1993 tentang Pedoman Tata laksana Pelayanan Umum, "Pelayanan masyarakat adalah segala bentuk kegiatan yang dilaksanakan instansi pemerintah di pusat, di daerah dalam membentuk barang dan jasa baik dalam bentuk pemenuhan masyarakat maupun dalam pelaksanaan ketentuan perundang-undangan".
\end{abstract}

Kata Kunci : Pelayanan, Indeks Kepuasan

\section{PENDAHULUAN}

\section{A. Latar Belakang}

Perkembangan jasa pelayanan publik di Indonesia telah mengalami perubahan dan kemajuan yang pesat sebagai akibat kemajuan teknologi, informasi, dan globalisasi. Selain itu masyarakat sebagai konsumen atau pengguna jasa semakin kritis dalam menentukan pilihan. Para konsumen tentunya menginginkan bahwa segala sesuatunya harus dilayani dengan mudah, cepat dan murah.

Rumah Sakit Budi Kemuliaan Batam adalah salah satu instansi pelayanan publik yang bergerak di bidang jasa pelayanan kesehatan. Jika dilihat dari segi pesaing Rumah Sakit Budi Kemuliaan Batam (RSBK Batam) merupakan rumah sakit yang memiliki sedikit pesaing. Di RSBK Batam yang dapat merasakan pelayanan secara langsung adalah keluarga dari pasien. Beberapa pelayanan yang dapat dirasakan oleh keluarga pasien antara lain tempat tunggu, tempat pemeriksaan pasien, apotik, tempat pembayaran, ruang konsultasi, dan lain-lain. Pada pelayanan tersebut ada beberapa keluarga pasien yang mengeluhkan akan pelayanan RSBK Batam. Ada beberapa keluarga yang tidak mengetahui letak pembayaran, tempat apotik, selain itu juga ada yang mengeluhkan tata cara untuk memasukkan pasien. Sehubungan dengan permasalahan ini maka akan dilakukan penelitian untuk mengetahui tingkat kepuasan keluarga pasien RSBK Batam. Indeks kepuasan keluarga pasien ini sangat penting perannya bagi RSBK Batam maupun bagi masyarakat. 
Salah satu upaya untuk mengetahui indeks kepuasan keluarga pasien dan guna meningkatkan kualitas pelayanan publik (termasuk rumah sakit ), sebagaimana diamanatkan dalam undang-undang Republik Indonesia Nomor 25 tahun 2000 tentang Program Pembangunan Nasional (PROPENAS), maka perlu disusun Indeks Kepuasan Masyarakat (IKM) sebagai tolok ukur untuk menilai tingkat kualitas pelayanan Rumah Sakit Budi Kemuliaan Batam pada masyarakat. Indeks Kepuasan Masyarakat (IKM) akan dapat menjadi bahan penilaian terhadap unsur pelayanan RSBK Batam yang masih perlu perbaikan dan menjadi pendorong setiap unit penyelenggara pelayanan RSBK Batam untuk meningkatkan kualitas pelayanan.

\section{B. Rumusan Masalah}

Berapa indeks kepuasan keluarga pasien terhadap kualitas pelayanan Rumah Sakit Budi Kemuliaan Batam

\section{Tujuan Penelitian}

Tujuan dari penelitian ini adalah untuk mengetahui indeks kepuasan keluarga pasien terhadap pelayanan Rumah Sakit Budi Kemuliaan Batam.

\section{Manfaat Penelitian}

1. Bagi Peneliti

Sebagai pengembangan dan penerapan ilmu yang didapatkan.

2. Bagi Rumah Sakit Budi Kemuliaan Batam :

1) Sebagai masukan/informasi guna pengambilan keputusan/penentu kebijakan Direktur Rumah Sakit Budi Kemuliaan Batam .

2) Sebagai bahan pertimbangan dalam upaya pengembangan sistem kualitas pelayanan yang telah ada.

3) Dapat mengetahui kelemahan dan kekurangan dari masing-masing unsur dalam pelayanan.

\section{Bagi Masyarakat}

Sebagai gambaran tentang kinerja pelayanan RSBK Batam

\section{TINJAUAN TEORITIS}

\section{A. Kepuasan Pelanggan}

Tidak semua pelanggan yang menggunakan suatu jasa merasa senang akan hasilnya. Bahkan ada yang sama sekali kecewa dan tidak akan menggunakan jasa tersebut lagi. Kepuasan adalah perasaan senang atau kecewa sseorang yang mucul setelah membandingkan antara kinerja (hasil) produk yang dipikirkan terhadap kinerja yang diharapkan. Jika kinerja berada di bawah harapan, pelanggan tidak puas. Jika kinerja memenuhi harapan, pelanggan puas. Jika kinerja melebihi harapan, pelanggan amat puas atau senang. (Kotler, 2003 : 70). Pelanggan umumnya mengharapkan produk berupa barang atau jasa yang dikonsumsi dapat diterima dan dinikmatinya dengan pelayanan yang baik atau memuaskan (Assauri, 2003: 28). Semua 
pelanggan memiliki harapan seperti apa yang dikatakan oleh Assauri, inilah yang menjadikan suatu penyedia barang atau jasa suatu tantangan.

Kepuasan adalah perbandingan antara apa yang diharapkan dengan apa yang diterima atau dirasakan (perceived performance) adalah sama atau melebihi. Loyalitas terjadi bila pelanggan sangat puas atau apa yang diterimanya lebih besar dari apa yang diharapkannya. Supriyanto, (Sumarmi, 2006:4). Kepuasan pelanggan telah menjadi konsep sentral dalam wacana bisnis dan manajemen (Tjiptono, 2005: 192). Kepuasan pasien didefinisikan sebagai evaluasi pasca konsumsi bahwa suatu produk yang dipilih setidaknya memenuhi atau melebihi harapan. Kepuasan merupakan pengalaman yang akan mengendap di dalam ingatan pasien sehingga mempengaruhi proses pengambilan keputusan pembelian ulang produk yang sama. Endang (Harianto:2003). Para pelanggan akan mencari produk berupa barang atau jasa dari perusahaan yang dapat memberikan pelayanan yang terbaik kepadanya (Assauri, 2003:25).

Untuk merencanakan langkah perusahaan selanjutnya diperlukan evaluasi kepuasan pelanggan, agar mengetahui secara pasti kelemahan dari pelayanan yang diberikan selama ini. Menurut Kotler (2003:72), ada beberapa cara untuk mengukur tingkat kepuasan pelanggan, yaitu:

1. Sistem keluhan dan saran;

2. Survey kepuasan pelanggan;

3. Pembeli bayangan;

4. Analisis pelanggan yang beralih;

\section{B. Pelayanan}

Sebuah jasa akan berkaitan sekali dengan pelayanan. Jika sebuah pelayanan bagus maka identik dengan hasil jasanya yang bagus, meskipun belum tentu pelayanan bagus jasa yang dihasilkan pasti bagus.

Pelayanan prima merupakan suatu layanan yang diberikan kepada publik yang mampu memuaskan pihak yang dilayani, hal tersebut sebagaimana disebutkan dalam SK Menpan No. 81 Tahun 1993 tentang Pedoman Tata laksana Pelayanan Umum, "Pelayanan masyarakat adalah segala bentuk kegiatan yang dilaksanakan instansi pemerintah di pusat, di daerah dalam membentuk barang dan jasa baik dalam bentuk pemenuhan masyarakat maupun dalam pelaksanaan ketentuan perundang-undangan".

Mutu pelayanan yang baik, yang memuaskan dari sudut pasien dikaitkan dengan masalah kesembuhan, meningkatkan derajat kesehatan atau kebugaran, kecepatan pelayanan, persepsi terhadap lingkungan fisik dan kenyamanan serta tarif yang sesuai dengan kondisi sosial ekonomi pasien. (Jacobalis, 1990).

Menurut (Rangkuti, 2002 : 29) ada sepuluh kriteria umum atau standart yang menentukan kualitas suatu pelayanan dan jasa, yaitu :

1. Reability (keandalan)

2. Respon (ketanggapan)

3. Competence (kemampuan)

4. Assess (mudah diperoleh)

5. Courtesy (keramahan)

6. Communication (komunikasi)

7. Credibility (dapat dipercaya)

8. Security (keamanan)

9. Understanding/knowing the costumer 
10. Tangible (bukti nyata yang kasat mata)

Kesepuluh dimensi tersebut dapat disederhanakan menjadi lima dimensi, yaitu :

1. Responsiveness (ketanggapan),

2. Reliability (kehandalan),

3. Assurance (jaminan),

4. Emphaty (empati),

5. Tangibles (bukti langsung),

\section{Indeks Kepuasan Masyarakat (IKM)}

\section{a) Pengertian Umum}

Pada pedoman ini yang dimaksud dengan :

1. Indeks Kepuasan Masyarakat (IKM) adalah data dan informasi tentang tingkat kepuasan masyarakat yang diperoleh dari hasil pengukuran secara kuantitatif dan kualitatif atas pendapat masyarakat dalam memperoleh pelayanan dari aparatur penyelenggara pelayanan publik dengan membandingkan antara harapan dan kebutuhannya.

4. Pelayanan publik adalah segala kegiatan pelayanan yang dilaksanakan oleh penyelenggara pelayanan publik sebagai upaya pemenuhan kebutuhan penerima pelayanan, maupun dalam rangka pelaksanaan ketentuan peraturan perundangundangan.

5. Unit pelayanan publik adalah unit kerja/kantor pelayanan pada instansi pemerintah termasuk BUMN/BUMD dan BHMN, yang secara langsung maupun tidak langsung memberikan pelayanan kepada penerima pelayanan.

6. Penerima pelayanan publik adalah orang, masyarakat, lembaga instansi pemerintah dan dunia usaha, yang menerima pelayanan dari aparatur penyelenggara pelayanan publik.

7. Kepuasan pelayanan adalah hasil pendapat dan penilaian masyarakat terhadap kinerja pelayanan yang diberikan oleh aparatur penyelenggara pelayanan publik.

8. Biaya pelayanan publik adalah segala biaya (dengan nama atau sebutan apapun) sebagai imbal jasa atas pemberian pelayanan publik, yang besaran dan tatacara pembayarannya ditetapkan oleh pejabat yang berwenang .

9. Unsur pelayanan adalah faktor atau aspek yang terdapat dalam penyelenggaraan pelayanan kepada masyarakat sebagai variabel penyusunan indeks kepuasan masyarakat untuk mengetahui kinerja unit pelayanan.

10. Responden adalah penerima pelayanan publik yang pada saat pencacahan sedang berada di lokasi unit pelayanan, atau yang pernah menerima pelayanan dari aparatur penyelenggara pelayanan.

\section{b). Unsur Indeks Kepuasan Masyarakat}

Berdasarkan prinsip pelayanan sebagaimana telah ditetapkan dalam Keputusan Men.PAN Nomor : 63/KEP/M.PAN/7/2003, yang kemudian dikembangkan menjadi 14 unsur 
yang "relevan, valid" dan "reliabel", sebagai unsur minimal yang harus ada untuk dasar pengukuran indeks kepuasan masyarakat adalah sebagai berikut:

1. Prosedur pelayanan, yaitu kemudahan tahapan pelayanan yang diberikan kepada masyarakat dilihat dari sisi kesederhanaan alur pelayanan;

2. Persyaratan Pelayanan, yaitu persyaratan teknis dan administratif yang diperlukan untuk mendapatkan pelayanan sesuai dengan jenis pelayanannya;

3. Kejelasan petugas pelayanan, yaitu keberadaan dan kepastian petugas yang memberikan pelayanan (nama, jabatan serta kewenangan dan tanggung jawabnya);

4. Kedisiplinan petugas pelayanan, yaitu kesungguhan petugas dalam memberikan pelayanan terutama terhadap konsistensi waktu kerja sesuai ketentuan yang berlaku;

5. Tanggung jawab petugas pelayanan, yaitu kejelasan wewenang dan tanggung jawab petugas dalam penyelenggaraan dan penyelesaian pelayanan;

6. Kemampuan petugas pelayanan, yaitu tingkat keahlian dan ketrampilan yang dimiliki petugas dalam memberikan/ menyelesaikan pelayanan kepada masyarakat;

7. Kecepatan pelayanan, yaitu target waktu pelayanan dapat diselesaikan dalam waktu yang telah ditentukan oleh unit penyelenggara pelayanan;

8. Keadilan mendapatkan pelayanan, yaitu pelaksanaan pelayanan dengan tidak membedakan golongan/status masyarakat yang dilayani;

9. Kesopanan dan keramahan petugas, yaitu sikap dan perilaku petugas dalam memberikan pelayanan kepada masyarakat secara sopan dan ramah serta saling menghargai dan menghormati;

10. Kewajaran biaya pelayanan, yaitu keterjangkauanmasyarakat terhadap besarnya biaya yang ditetapkan oleh unit pelayanan;

11. Kepastian biaya pelayanan, yaitu kesesuaian antara biaya yang dibayarkan dengan biaya yang telah ditetapkan;

12. Kepastian jadwal pelayanan, yaitu pelaksanaan waktu pelayanan, sesuai dengan ketentuan yang telah ditetapkan;

13. Kenyamanan lingkungan, yaitu kondisi sarana dan prasarana pelayanan yang bersih, rapi, dan teratur sehingga dapat memberikan rasa nyaman kepada penerima pelayanan;

14. Keamanan Pelayanan, yaitu terjaminnya tingkat keamanan lingkungan unit penyelenggara pelayanan ataupun sarana yang digunakan, sehingga masyarakat merasa tenang untuk mendapatkan pelayanan terhadap resiko-resiko yang diakibatkan dari pelaksanaan pelayanan.

\section{c) Konsumen}

Ada dua pihak yang terlibat dalam proses jasa/pelayanan, yaitu penyedialayanan (pelayan) dan konsumen (yang dilayani). Munurut Wahyuddin dan Muryati (2001: 191), dalam pelayanan yang disebut konsumen (customer) adalah masyarakat yang mendapat manfaat dari aktivitas yang dilakukan oleh organisasi atau petugas dari organisasi pemberi layanan tersebut.

Dalam mengembangkan organisasi yang berorientasi konsumen (customer oriented), maka semua kegiatan harus berbasis pada kebutuhan dan keinginan pelanggan (customer needs 
and wants) dan persepsi konsumen terhadap nilai dan mutu suatu produk (barang dan jasa) banyak dipengaruhi oleh pelayanan prima sebagai atribut yang melekat pada prodnk inti itu sendiri. Saragih (Sumarmi, $2006: 24$ ).

\section{III.METODOLOGI PENELITIAN}

1. Lokasi dan Waktu Penelitian

1. Lokasi Penelitian

Lokasi penelitian adalah di unit pelayanan Rumah Budi Kemuliaan Batam Jl. Budi Kemuliaan No 1 Batam

2. Waktu Penelitian

Waktu Penelitian selama empat bulan, mulai Januari 2011 sampai dengan April 2011

\section{Jumlah Responden}

Responden dipilih secara acak yang dintentukan sesuai dengan cakupan wilayah pelayanan. Untuk memenuhi akurasi hasil penyusunan indeks, responden terpilih ditetapkan minimal 150 orang dari jumlah populasi penerima layanan, dengan dasar ("Jumlah unsur" +1 ) x $10=$ jumlah responden $(14+1)$ x $10=150$ responden.

\section{Variabel penelitan}

Variabel penelitan ini adalah Kepuasan Masyarakat (keluarga pasien) atas Pelayanan di Rumah Sakit Budi Kemuliaan Batam

\section{Metode Pengumpulan data}

Metode Pengumpulan Data adalah metode yang dilakukan untuk menghasilkan data dan informasi yang diperlukan serta berhubungan dengan hal yang akan ditulis. Untuk mengumpulkan data serta informasi yang diperlukan oleh penulis menggunakan metode sebagai berikut :

\section{Penelitian Lapangan (Field Research)}

Penelitian ini dilakukan untuk mendapatkan data primer dengan cara mendatangi objek yang akan diteliti. Tujuan yang diharapkan adalah untuk memperoleh data secara langsung dari pihak perusahaan. Teknik yang dipergunakan adalah :

\section{○ Daftar Pertanyaan (Questionaire)}

\section{○ Wawancara (Interview).}

\section{Penelitian Kepustakan (Library Research).}

Dalam penulisan ini cara yang pertama penulis sajikan melalui pengamatan data yang dilakukan dengan cara membaca, mempelajari dan mengutip dari buku literatur, majalah, serta sumber-sumber lain yang berhubungan erat dengan penulisan ini.

\section{Teknik Analisa data}

Nilai IKM dihitung dengan menggunakan "nilai rata-rata tertimbang" masing-masing unsur pelayanan. Dalam perhitungan indeks kepuasan masyarakat terdapat 14 unsur pelayanan yang dikaji, setiap unsur pelayanan mempunyai penimbang yang sama dengan rumus sebagai berikut :

Bobot nilai rata2

$$
=\underline{\text { Jumlah bobot }}=1 / 14=0,071
$$


Untuk memperoleh nilai IKM unit pelayanan digunakan pendekatan nilai rata-rata tertimbang dengan rumus sebagai berikut :

\section{IKM $=\underline{\text { Total dari nilai persepsi per unsur }} \quad x \quad$ Nilai Penimbang Total unsur yang terisi}

Untuk memudahkan interpretasi terhadap penilaian IKM yaitu antara $25-100$, maka hasil penilaian tersebut diatas dikonversikan dengan nilai dasar 25 , dengan rumus sebagai berikut :

\section{IKM unit Pelayanan x 25}

Nilai persepsi, internal IKM, Interval Konversi IKM, Mutu Pelayanan dan Kinerja Unit Pelayanan

\begin{tabular}{|c|c|c|c|c|}
\hline Nilai persepsi & $\begin{array}{c}\text { Niali interval } \\
\text { IKM }\end{array}$ & $\begin{array}{c}\text { Nilai interval } \\
\text { konversi IKM }\end{array}$ & Mutu Pelayanan & $\begin{array}{c}\text { Kinerja Unit } \\
\text { Pelayanan }\end{array}$ \\
\hline 1 & $1,00-1,75$ & $25,00-43,75$ & $\mathrm{~d}$ & Tidak Baik \\
\hline 2 & $1,76-2,50$ & $43,76-62,50$ & $\mathrm{c}$ & Kurang Baik \\
\hline 3 & $2,51-3,25$ & $62,51-81,25$ & $\mathrm{~b}$ & Baik \\
\hline 4 & $3,26-4,00$ & $81,26-100$ & $\mathrm{a}$ & Sangat Baik \\
\hline
\end{tabular}

Sumber : Kep. Men.Pan Nomor Kep/25/M.PAN/2/2004 Pedoman Umum Penyusunan IKM

\section{HASIL PENELITIAN DAN PEMBAHASAN}

\subsection{PROFIL SUBJEK PENELITIAN}

\subsubsection{GAMBARAN RUMAH SAKIT BUDI KEMULIAAN BATAM}

Rumah Sakit Budi Kemuliaan Batam pertama kali didirikan tahun 1992 dengan tujuan meningkatkan derajat kesehatan rakyat, ini sesuai dengan surat persetujuan dari Kepala Kantor Departemen Kesehatan Kodya Batam dengan no. 2210/Kandep/KU-4/1992 dan surat dari Kepala satuan Pelaksanaan Otorita Pengembangan Daerah Industri Pulau Batam no. 14/KEP/KA/IMB/I/1991 tanggal 17 Januari 1991. Berdasarkan surat tersebut diatas maka oleh Departemen Kesehatan Republik Indonesia Kantor Wilayah Propinsi Riau dikelaurkan izin Pendirian Rumah Sakit Umum Budi Kemualiaan Batam dengan no 10320/KANWIL/K2/XI/1992 tanggal 22 November 1992 dimana surat ini hanya berlaku untuk satu tahun dan dapat diperpanjang kembali, maka pada tahun 1993 oleh Kanwil Departemen Kesehatan Provinsi Riau dikeluarkan izin sementara Rumah Sakit Budi Kemuliaan Batam dengan nomor keputusan 959/Kanwil/PK-2/XII/1993. Dan berdasarkan surat keputusan Menteri Kesehatan Republik Indonesia No. YM 02.04.00.0.922 yang dikeluarkan pada tanggal 12 Maret 2001 memberikan izin penyelenggaraan kepada Dewan Pengurus Perkumpulan Budi Kemuliaan Batam untuk menyelenggarakan rumah sakit umum - Rumah Sakit Budi Kemuliaan Batam. Izin ini berlaku selama 5 tahun semenjak dikeluarkannya surat keputusan ini. Dan semenjak 
tahun 2002 Rumah Sakit Budi Kemuliaan telah mendirikan Akademi Perawat sebagai penunjang kegiatan Rumah Sakit Budi Kemuliaan Batam.

Sebagai penjabaran dari pada maksud pengembangan RS. Budi Kemuliaan Batam (RSBK) agar tetap eksis dan diminati oleh pasien disegala lapisan masyarkat dan karyawan sesuai cita-cita yang diharapkan, manajemen menuangkan visi sebagai berikut :

\section{"Sebagai sarana pelayanan kesehatan profesional dan terjangkau".}

Sebagai penerapan (Aplikasi) visi diatas, maka untuk jangka panjang dituangkan didalam misi sebagai berikut :

1. Menerapkan manajemen rumah sakit yang profesional

2. Memberikan pelayanan kesehatan yang berkualitas dan terjangkau

3. Mengoptimalkan SDM - Sumber Daya Manusia dan teknolgi kesehatan yang tepat guna.

4. Menjadi mitra sinergis dengan pihak lain dalam meningkatkan pelayanan kesehatan.

Adalah sesuatu yang hendak dicapai secara global, dalam mengemban visi dan misi RSBK, maka tujuan yang hendak dicapai adalah :

1. Membantu pemerintah dibidang pelayanan kesehatan.

2. Membantu menigkatkan kesehatan masyarakat

3. Memberikan peluang kerja kepada tenaga medis dan non medis

4. Membentuk sumber daya manusia yang berkualitas dibidang kesehatan.

RS. Budi Kemuliaan hingga akhir tahun 2009 melaksanakan beberapa kegiatan operasional, yaitu : (1) Pelayanan Medis/Poliklnik, yang terdiri dari : (a) Spesialis Bedah, (b) Spesialis Kandungan dan Kebidanan, (c) Spesialis Penyakit Dalam, (d) Spesialis Anak, (e) Spesialis THT, (f) Spesialis Mata, (g) Spesialis Jantung dan Pembuluh Darah, (h) Spesialis Paru dan Pernapasan, (i) Spesialis Bedah Syaraf, (j) Dokter Umum, dan (k) Dokter Gigi, (2) Sarana Diagnostik dan Pengobatan, yang terdiri dari : (a) Istalasi Gawat Darurat 24 Jam, (b) Medical Check Up, (c) Laboratorium Klnik 24 Jam, (d) Medical Check Up, (e) Kamar Operasi, (f) Unit Hemodialysis, (g) Ultrasonografi (USG), (h) Echo Kardiografi, (i) Fisioterapi, (j) ICU/NICU, dan (3) Fasilitas Penunjang, yang terdiri dari : (a) Farmasi/Apotek 24 Jam, (b) Ambulance 24 Jam, (c) Bank Darah, (d) PMI - Palang Merah Indonesia, (e) Bagian Gizi, (f) Pengelolaan Limbah, (g) Ruang Cuci (Laundry), (h) Dapur Besar, (i) Kantin Karyawan

Struktur organisasi pada bidang keperawatan di Rumah Sakit Budi Kemuliaan Batam adalah struktur organisasi yang disusun berdasarkan fungsi pelayanan dan fungsi administrasi, sehingga penugasan setiap perawat menjadi terspesialisasi dan terarah untuk meningkatkan layanan secara profesional kepada pasien serta menunjang keberhasilan tujuan Rumah Sakit Budi Kemuliaan Batam.

\subsection{HASIL PENELITIAN}

\subsubsection{KARAKTERISTIK RESPONDEN}

Dari hasil penelitian kepada semua responden di RSBK Batam, didapatkan karakteristik responden sebagai berikut :
1. Jenis Pelayanan
: Rawat Jalan, Rawat Inap
2. Jenis Pembayaran
: Perusahaan (Asuransi), Umum
3. Jenis Kelamin
: Laki-laki, Perempuan
4. Umur
: 15-25, 26-35, 36-45, > 45 tahun
5. Asal Kota
: Dalam Kota, Luar Kota Batam 


\subsubsection{Karakteristik Responden menurut Jenis Pelayanan}

Tabel 4.1

Karakteristik Responden menurut Jenis Pelayanan di RSBK Batam

\begin{tabular}{|c|c|r|r|l|}
\hline \hline No. & Jenis Pelayanan & $\begin{array}{r}\text { Jumlah } \\
\text { Respon. }\end{array}$ & $\%$ & Keterangan \\
\hline \hline 1 & Rawat Jalan & 100 & 33,3 & \\
\hline 2 & Rawat Inap & 50 & 66,7 & \\
\hline \multicolumn{2}{|c|}{ Jumlah } & 150 & 100 & \\
\hline
\end{tabular}

Sumber : Data primer diolah

Menurut Tabel 4.1 dari 150 responden, sebanyak 100 responden $(66,7 \%)$ rawat jalan dan sebanyak 50 responden $(33,3 \%)$ rawat inap di RSBK Batam.

\subsubsection{Karakteristik Responden menurut Jenis Pembayaran}

Tabel 4.2

Karakteristik Responden menurut Jenis Pembayaran di RSBK Batam

\begin{tabular}{|c|l|c|c|c|}
\hline \hline No. & Jenis Kelamin & $\begin{array}{c}\text { Jumlah } \\
\text { Respon. }\end{array}$ & $\%$ & Keterangan \\
\hline \hline 1 & $\begin{array}{l}\text { Perusahaan } \\
\text { (Asuransi) }\end{array}$ & 90 & 60 & \\
\hline 2 & Umum & 60 & 40 & \\
\hline \multicolumn{2}{|c|}{ Jumlah } & 150 & 100 & \\
\hline
\end{tabular}

Sumber : Data primer diolah

Menurut Tabel 4.2 dari 150 responden, sebanyak 90 responden (60\%) Perusahaan (Umum) dan sebanyak 40 responden (40\%) Umum di RSBK Batam, lebih jelasnya dapat dilihat pada gambar 5.3. berikut ini :

\subsubsection{Karakteristik Responden menurut Jenis Kelamin}

Tabel 4.3

Karakteristik Responden menurut Jenis Kelamin di RSBK Batam

\begin{tabular}{|c|l|c|c|c|}
\hline \hline No. & Jenis Kelamin & $\begin{array}{r}\text { Jumlah } \\
\text { Respon. }\end{array}$ & $\%$ & Keterangan \\
\hline 1 & Laki-laki & 78 & 52 & \\
\hline 2 & Perempuan & 72 & 48 & \\
\hline \multicolumn{2}{r|}{ Jumlah } & 150 & 100 & \\
\hline
\end{tabular}

Sumber : Data primer diolah

Menurut Tabel 4.3 dari 150 responden, sebanyak 78 responden (52\%) berjenis kelamin laki-laki dan sebanyak 72 responden (48 \%) berjenis kelamin perempuan, berkunjung di RSBK Batam.

\subsubsection{Karakteristik Responden menurut Umur}

Tabel 4.4 
Karakteristik Responden menurut Umur di RSBK Batam

\begin{tabular}{|c|c|r|r|l|}
\hline \hline No. & Jenis Kelamin & $\begin{array}{c}\text { Jumlah } \\
\text { Respon. }\end{array}$ & \multicolumn{1}{c|}{ Keterangan } \\
\hline \hline 1 & $15-25$ & 25 & 17 & \\
\hline 1 & $26-35$ & 60 & 40 & \\
\hline 2 & $36-45$ & 51 & 34 & \\
\hline 3 & $>45$ & 14 & 9 & \\
\hline & Jumlah & 150 & 100 & \\
\hline
\end{tabular}

Sumber : Data primer diolah

Menurut Tabel 4.4 dari 150 responden, sebanyak 25 responden (17\%) umur 15-25 tahun, sebanyak 60 responden (40\%) 26-35 tahun, sebanyak 51 responden (34\%) umur 36-45 tahun, sebanyak 14 responden ( $9 \%$ ) umur $>45$ tahun di RSBK Batam.

\subsubsection{Karakteristik Responden menurut Asal Kota}

Tabel 4.5

Karakteristik Responden menurut Asal Kota di RSBK Batam

\begin{tabular}{|c|l|r|r|l|}
\hline No. & Jenis Pelayanan & $\begin{array}{c}\text { Jumlah } \\
\text { Respon. }\end{array}$ & $\%$ & Keterangan \\
\hline \hline 1 & Dalam Kota Batam & 94 & 62,7 & \\
\hline 2 & Luar Kota Batam & 56 & 37,3 & \\
\hline \multicolumn{2}{|c|}{ Jumlah } & 150 & 100 & \\
\hline
\end{tabular}

Sumber : Data primer diolah

Menurut Tabel 4.5 dari 150 responden, sebanyak 94 responden (62,7\%) dalam kota Surabaya dan sebanyak 56 responden (37,3 \%) luar kota Batam di RSBK Batam.

\subsubsection{NILAI RATA-RATA BERDASARKAN KARAKTERISTIK}

\subsubsection{Unsur Pelayanan berdasarkan Nilai Rata-rata Jenis Pelayanan}

Tabel 4.6

Unsur Pelayanan berdasarkan Nilai Rata-rata Jenis Pelayanan

\begin{tabular}{|c|c|l|c|c|}
\hline \multirow{2}{*}{ NO. } & \multirow{2}{*}{ KODE } & \multicolumn{2}{|c|}{ UNSUR PELAYANAN } & \multicolumn{2}{|c|}{$\begin{array}{c}\text { NILAI RATA- } \\
\text { RATA }\end{array}$} \\
\cline { 4 - 5 } & & & $\begin{array}{c}\text { RAWAT } \\
\text { JALAN }\end{array}$ & $\begin{array}{c}\text { RAWAT } \\
\text { INAP }\end{array}$ \\
\hline \hline 1 & $\mathrm{U} 1$ & Prosedur pelayanan & 2,88 & 2,88 \\
\hline 2 & $\mathrm{U} 2$ & Persyaratan pelayanan & 3,00 & 2,96 \\
\hline 3 & $\mathrm{U} 3$ & Kejelasan petugas pelayanan & 2,98 & 2,99 \\
\hline
\end{tabular}




\begin{tabular}{|c|c|l|c|c|}
\hline \hline \multirow{2}{*}{ NO. } & \multirow{2}{*}{ KODE } & \multicolumn{1}{|c|}{ UNSUR PELAYANAN } & \multicolumn{2}{c|}{$\begin{array}{c}\text { NILAI RATA- } \\
\text { RATA }\end{array}$} \\
\hline 4 & U4 & Kedisiplinan petugas pelayanan & 2,98 & 2,93 \\
\hline 5 & U5 & Tanggung jawab petugas pelayanan & 3,04 & 2,96 \\
\hline 6 & U6 & Kemampuan petugas pelayanan & 2,90 & 3,01 \\
\hline 7 & U7 & Kecepatan pelayanan & 3,00 & 2,84 \\
\hline 8 & U8 & Keadilan mendapatkan pelayanan & 2,90 & 3,02 \\
\hline 9 & U9 & Kesopanan dan keramahan petugas & 3,00 & 3,00 \\
\hline 10 & U10 & Kewajaran biaya pelayanan & 3,00 & 2,97 \\
\hline 11 & U11 & Kepastian biaya pelayanan & 3,06 & 3,55 \\
\hline 12 & U12 & Kepastian jadwal pelayanan & 2,96 & 3,31 \\
\hline 13 & U13 & Kenyamanan lingkungan & 3,00 & 3,03 \\
\hline 14 & U14 & Keamanan pelayanan & 3,06 & 2,99 \\
\hline
\end{tabular}

Sumber : Data primer diolah

Pada Tabel 4.6. secara umum dapat dilihat bahwa keluarga pasien rawat jalan dan rawat inap untuk unsure U1 (prosedur pelayanan) memiliki nilai rata-rata 2,88 (masih memenuhi kriteria baik/puas). Pada rawat jalan untuk unsur pelayanan U11 (kepastian biaya pelayanan) nilai rata-rata 3,55 dan U12 (kepastian jadwal pelayanan) nilai rata-rata 3,31, meningkat tajam masuk kriteria sangat baik/sangat puas. Sedangkan untuk pasien rawat jalan tetap stabil seperti pada unsur lainnya. Batas nilai rata-rata puas adalah 2,51-3,25.

\subsubsection{Unsur Pelayanan berdasarkan Nilai Rata-rata Jenis Pembayaran}

Tabel 4.7

Unsur Pelayanan berdasarkan Nilai Rata-rata Jenis Pembayaran

\begin{tabular}{|c|c|l|c|c|}
\hline \hline \multirow{2}{*}{ NO. } & \multirow{2}{*}{ KODE } & \multicolumn{1}{|c|}{ UNSUR PELAYANAN } & \multicolumn{2}{|c|}{$\begin{array}{c}\text { NILAI RATA- } \\
\text { RATA }\end{array}$} \\
\cline { 4 - 6 } & & & GAKIN & UMUM \\
\hline \hline 1 & $\mathrm{U} 1$ & Prosedur pelayanan & 2.86 & 2.92 \\
\hline 2 & $\mathrm{U} 2$ & Persyaratan pelayanan & 2.86 & 2.95 \\
\hline \hline NO. & KODE & UNSUR PELAYANAN & \multicolumn{2}{|c|}{ NILAI RATA- } \\
RATA
\end{tabular}




\begin{tabular}{|c|c|l|c|c|}
\cline { 3 - 3 } 8 & U8 & Keadilan mendapatkan pelayanan & 3.06 & 2.87 \\
\hline 9 & U9 & Kesopanan dan keramahan petugas & 2.96 & 3.00 \\
\hline 10 & U10 & Kewajaran biaya pelayanan & 2.93 & 3.03 \\
\hline 11 & U11 & Kepastian biaya pelayanan & 3.51 & 3.20 \\
\hline 12 & U12 & Kepastian jadwal pelayanan & 3.40 & 2.88 \\
\hline 13 & U13 & Kenyamanan lingkungan & 3.06 & 2.97 \\
\hline 14 & U14 & Keamanan pelayanan & 3.00 & 3.03 \\
\hline
\end{tabular}

Sumber : Data primer diolah

Pada Tabel 4.7. secara umum dapat dilihat bahwa keluarga pasien umum untuk unsur U6 (kemampuan pelayanan) memiliki nilai rata-rata 2,85 (masih memenuhi kriteria baik/puas). Pada perusahaan (asuransi) untuk unsur pelayanan U11 (kepastian biaya pelayanan) nilai ratarata 3,51 dan U12 (kepastian jadwal pelayanan) nilai rata-rata 3,40, meningkat tajam masuk kriteria sangat baik/sangat puas. Batas nilai rata-rata puas adalah 2,51-3,25.

\subsubsection{Penilaian Unsur Indeks Kepuasan Masyarakat}

Data dalam kuesioner diolah dan didapatkan nilai perunsur pelayanan. Adapun hasil dari pengolahan data adalah sebagai berikut :

Tabel 4.8

Nilai Rata-rata Per Unsur Pelayanan di RSBK Batam

\begin{tabular}{|l|l|c|c|c|c|}
\hline \multirow{2}{*}{ No. } & \multicolumn{2}{|c|}{ Unsur Pelayanan } & \multirow{2}{*}{ Kode } & \multirow{2}{*}{$\begin{array}{c}\text { Nilai } \\
\text { Rata-rata }\end{array}$} & \multicolumn{2}{|c|}{ Batas Nilai Baik } \\
\cline { 5 - 6 } & & & Min. & Mak. \\
\hline 1 & Prosedur pelayanan & 2,88 & 2,51 & 3,25 \\
\hline No. & \multicolumn{1}{|c}{ Unsur Pelayanan } & Kode & $\begin{array}{c}\text { Nilai } \\
\text { Rata-rata }\end{array}$ & Batas Nilai Baik \\
\hline 2 & Persyaratan pelayanan & U2 & 2,97 & 2,51 & 3,25 \\
\hline 3 & Kejelasan petugas pelayanan & $\mathrm{U} 3$ & 2,99 & 2,51 & 3,25 \\
\hline 4 & Kedisiplinan petugas pelayanan & $\mathrm{U} 4$ & 2,95 & 2,51 & 3,25 \\
\hline 5 & Tanggung jawab petugas pelayanan & $\mathrm{U} 5$ & 2,99 & 2,51 & 3,25 \\
\hline 6 & Kemampuan petugas pelayanan & $\mathrm{U} 6$ & 2,97 & 2,51 & 3,25 \\
\hline 7 & Kecepatan pelayanan & $\mathrm{U} 7$ & 2,89 & 2,51 & 3,25 \\
\hline 8 & Keadilan mendapatkan pelayanan & $\mathrm{U} 8$ & 2,98 & 2,51 & 3,25 \\
\hline 9 & Kesopanan dan keramahan petugas & $\mathrm{U} 9$ & 2,97 & 2,51 & 3,25 \\
\hline 10 & Kewajaran biaya pelayanan & $\mathrm{U} 10$ & 2,97 & 2,51 & 3,25 \\
\hline 11 & Kepastian biaya pelayanan & $\mathrm{U} 11$ & 3,39 & 2,51 & 3,25 \\
\hline 12 & Kepastian jadwal pelayanan & $\mathrm{U} 12$ & 3,19 & 2,51 & 3,25 \\
\hline
\end{tabular}




\begin{tabular}{|l|l|c|c|c|c|}
13 & Kenyamanan lingkungan & $\mathrm{U} 13$ & 3,02 & 2,51 & 3,25 \\
\hline 14 & Keamanan pelayanan & $\mathrm{U} 14$ & 3,01 & 2,51 & 3,25 \\
\hline
\end{tabular}

Sumber : Data primer diolah

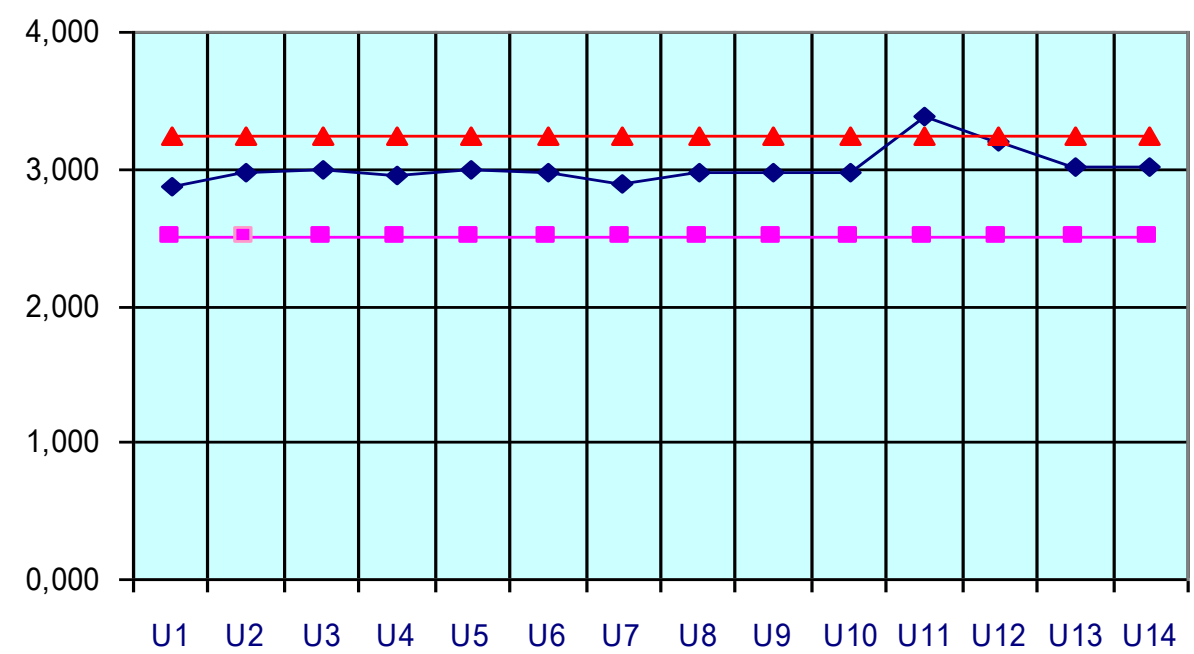

Batas minimun

Nilai Rata-rata Perunsur

Batas maksimum

Gambar 4.1

Grafik Nilai Rata-rata Per unsur Pelayanan dengan batas Minimum dan Maksimum kriteria baik di RSBK Batam

Pada Gambar 4.1 dapat dilihat nilai rata-rata kepuasan keluarga pasien (responden) per unsur serta batas minimum ataupun maksimum kepuasan. Pada unsur U1 (prosedur pelayanan) dengan nilai rata-rata 2,88, U7 (kecepatan palayanan) dengan nilai rata-rata 2,89, terjadi sedikit penurunan nilai rata-rata sedangkan pada unsur U11 (kepastian baiaya pelayanan) dengan nilai 3,39 dan U12 (kepastian jadwal pelayanan) dengan nilai 3,19 terjadi peningkatan nilai ratarata. Unsur dengan nilai rata-rata terendah adalah U1 (prosedur pelayanan) dengan nilai 2,88 (kategori baik) dan nilai rata-rata tertinggi adalah U11 (kepastian baiaya pelayanan) dengan nilai rata-rata 3,39 (nilai sangat baik).

Nilai indeks kepuasan masyarakat (IKM) pelayanan di RSBK Batam dihitung dengan rumus sebagai berikut :

$$
\begin{array}{rl} 
& (2,88 \times 0,071)+(2,97 \times 0,071)+(2,98 \times 0,071)+(2,95 \times 0,071)+ \\
& (2,99 \times 0,071)+(2,97 \times 0,071)+(2,89 \times 0,071)+(2,98 \times 0,071)+ \\
& (2,97 \times 0,071)+(2,97 \times 0,071)+(3,39 \times 0,071)+(3,19 \times 0,071)+ \\
& (3,02 \times 0,071)+(3,01 \times 0,071) \\
= & 0,204+0,211+0,212+0,209+0,212+0,211+0,205+0,212+0,211+0,211+0,240 \\
+0,227+0,214+0,214 & 2,994
\end{array}
$$

Untuk memudahkan interpretasi terhadap penilaian IKM yaitu antara 25 -100, maka hasil penilaian tersebut diatas dikonversikan dengan nilai dasar 25, dengan rumus Indeks Kepuasan Masyarakat dalam unit pelayanan dikalikan 25.

Unsur Indek terhadap pelayanan di RSJ Menur Surabaya sebagai berikut :

$$
\begin{aligned}
& =\text { IKM dalam unit pelayanan } \quad \text { X } 25 \\
& \begin{array}{llll}
= & 2,994 & \mathrm{X} & 25
\end{array} \\
& =74,86
\end{aligned}
$$

atau Mutu Pelayanan B 
artinya kinerja pelayanan RSBK Batam adalah Baik

\subsection{PEMBAHASAN HASIL}

\subsubsection{Unsur Pelayanan berdasarkan Nilai Rata-rata Jenis Pelayanan}

Nilai rata-rata kepuasan kelurga pasien yang didapatkan diatas nilai minimum rata-rata puas atau dapat dikatakan masih dalam kategori puas. Prosedur pelayanan memiliki nilai rata-rata paling kecil pada unsur ini. Hal ini dapat disebabkan keluarga pasien pada umumnya masih sedikit yang terbiasa/memahami prosedur yang ada pada RSBK Batam. Kepastian biaya pelayanan dan kepastian jadwal pelayanan pada jenis pelayanan rawat jalan berada dalam kategori sangat puas. Hal ini dapat disebabkan karena pada kepasitian biaya yang ada benar-benar diberlakukan, sehingga tidak ada suatu pungutan/tambahan apapun dari biaya yang telah ditetapkan. Kepastian jadwal dapat dikatakan hampir selalu tepat. Sedangkan kepastian biaya dan kepastian jadwal pada jenis pelayaan rawat inap mendapatkan nilai ratarata dalam kategori puas. Hal ini disebabkan karena pada rawat inap lebih banyak pos pelayanan dari pada rawat jalan sehingga ada kemungkinan pungutan biaya. Sehingga ada beberapa pos yang dimungkinkan ada perbedaan harga dari harga yang ditetapkan.

\subsubsection{Unsur Pelayanan berdasarkan Nilai Rata-rata Jenis Pembayaran}

Secara umum dapat dilihat bahwa keluarga pasien Umum pada unsur U1 (kemampuan pelayanan) sedikit memiliki nilai lebih rendah dibandingkan dengan keluarga pasien Perusahaan (Asuransi). Hal ini dapat disebabkan karena keluarga pasien Umum menganggap telah melakukan pembayaran, sehingga apabila mendapatkan pelayanan dengan kemampuan sama seperti Perusahaan (asuransi) akan merasakan kurang. Sedangkan Perusahaan (Asuransi) lebih tinggi karena menilai dirinya dilayani dengan pelayanan gratis maka hasil penialaiannya lebih tiggi dari umum. Begitu pula pada unsur U8 (keadilan pelayanan), keluarga pasien umum merasa mereka membayar maka ada sedikit perbedaan penilaian. Pada unsur pelayanan U11 (kepastian biaya pelayanan) dan U12 (kepastian jadwal pelayanan), keluarga pasien Perusahaan (Asuransi) meningkat tajam nilai rata-rata kepuasannya. Untuk kepuasan kepastian biaya keluarga pasien Perusahaan (Asuransi) memang mendapatkan subsidi/gratis sehingga merasa sangat puas. Sedangkan untuk kepastian jadwal pelayanan Perusahaan (Asuransi) juga merasa sangat puas dibandingkan dengan umum. Sedangkan untuk pasien umum pada unsur kepastian biaya meningkat sedikit dari pada unsur sebelumnya. Hal ini dikarenakan kepastian biaya pada RSBK Batam memang tidak ada pungutan biaya lainnya, sehingga dapat memuaskan para konsumennya, namum masih terlalu puas Perusahaan (Asuransi) karena mereka gratis. Tetapi pada kepastian jadwal pelayanan malah turun hal ini dapat disebabkan umum membutuhkan jadwal yang lebih pasti dari pada Perusahaan (Asuransi). Secara keseluruhan keluarga pasien (responden) merasakan puas akan pelayanan dari RSBK Batam.

\subsubsection{Pembahasan Unsur Indeks Kepuasan Masyarakat}

Secara umum responden (keluarga pasien) menyatakan puas dengan pelayanan RSJ Menur. Pada semua unsur responden menilai baik dan ada satu unsur pelayanan yang dinilai sangat baik. Pada unsur prosedur pelayanan mendapatkan nilai yang lebih rendah dari unsur yang lainnya dapat disebabkan adanya responden dari luar kota sehingga belum terbiasa dengan prosedur pelayanan pada RSBK Batam. Namun dapat pula karena ada beberapa prosedur RSBK Batam yang dinilai tidak sederhana oleh responden. Untuk rendahnya nilai dari unsur kecepatan pelayanan dapat disebabkan tidak adanya pemberitahuan lamanya suatu 
prosedur/layanan yang menyebabkan responden tidak mengetahui lamanya layanan tersebut. Hal ini dapat menyebabkan responden merasa lama.

Untuk kepastian biaya pelayanan responden menilai dengan sangat baik. Hal ini karena biaya yang sudah ditetapkan tidak ada lagi pungutan lain-lai. Sedangkan untuk kepastian jadwal responden menilai sedikit lebih tinggi dari unsur lainnya (meskipun tidak sangat baik). Hal ini dikarenakan jadwal yang telah dibuat dilaksanakan tepat waktu oleh para petugas. Namun ada halnya ada kepentingan mendadak pada orang yang bersangkutan namun tidak ada yang menggantikan sehinga ditunda.

Meskipun mendapatkan nilai IKM yang baik, diharapkan RSBK Batam dapat terus meningkatkan pelayanan kepada masyarakat karena fungsi dari Rumah Sakit adalah melayani masyarakat dengan sebaik-baiknya. Selain itu persaingan antar rumah sakit semakin tahun semakin berat dan konsumen lebih pintar serta banyak tuntutannya.

Unsur pelayanan yang sebaiknya lebih diutamakan pembenahannya adalah prosedur pelayanan, dibuat semakin sederhana, mudah dimengerti dan cocok diterapkan pada konsumen RSBK Batam. Saran yang dapat diberikan adalah dengan mengadakan penelitian tentang prosedur apa saja yang sesuai dengan keadaan RSBK Batam dan konsumennya. Salah satu cara dengan survei atau membuat kotak saran. Selain itu dapat menggunakan para petugas untuk aktif dalam memberikan informasi / pengarahan untuk prosedur selanjutnya dari pos pelayanan yang mereka jaga.

Selain prosedur pelayanan, unsur yang lebih diutamakan untuk dilakukan pembenahan adalah kecepatan pelayanan. Salah satu cara adalah dengan mengadakan pelatihan kepada petugas yang dianggap kecepatan pelayanannya kurang, lebih menyedehanakan prosedur pelayanan, memilih petugas yang aktif dan dapat pula dengan adanya pemberitahuan waktu yang dibutuhkan untuk setiap pelayanan.

\section{KESIMPULAN DAN SARAN}

\subsection{Kesimpulan}

Hasil dari pembahasan yang dilakukan dapat disimpulkan bahwa :

1. Indeks Kepuasan Masyarakat (IKM) RSBK Batam adalah $\mathbf{7 4 , 8 6}$ yang artinya kinerja pelayanan RSBK Batam adalah dalam kategori Baik.

2. Unsur pelayanan yang memiliki nilai rata-rata kepuasan paling rendah adalah prosedur pelayanan $(2,88)$ dan kecepatan pelayanan $(2,89)$.

3. Unsur pelayanan yang memiliki nilai rata-rata kepuasan paling tinggi adalah kepastian biaya $(3,39)$.

\subsection{Saran}

1. Unsur pelayanan yang sebaiknya lebih diutamakan pembenahannya adalah :

a. Prosedur pelayanan, dibuat semakin sederhana, mudah dimengerti dan cocok diterapkan pada konsumen RSBK Batam. Salah satu cara adalah dengan mengadakan penelitian tentang prosedur apa saja yang sesuai dengan keadaan RSBK Batam dan konsumennya.

b. Kecepatan pelayanan, Salah satu cara adalah dengan mengadakan pelatihan kepada petugas yang dianggap kecepatan pelayanannya kurang, lebih menyedehanakan prosedur pelayanan, memilih petugas yang aktif dan dapat pula dengan adanya pemberitahuan waktu yang dibutuhkan untuk setiap pelayanan. 
2. Saran untuk yang akan meneliti atau menindak lajuti dari penelitian ini adalah dapat membandingkan beberapa pengaruh kategori terhadap kepuasan masyarakat.

\section{DAFTAR PUSTAKA}

Assauri, Sofjan, 2003, Customer Service yang Baik Landasan Pencapaian Customer Satisfaction dalam Usahawan, No. 01, Tahun XXXII, Januari, hal.25-30. Jakarta

Harianto, 2003, Kepuasan Pasien Terhadap Pelayanan Resep di Apotek Kopkar Rumah Sakit Budhi Asih Jakarta, Tesis, Farmasi FMIPA, Universitas Indonesia, Jakarta.

Jacobalis, Samsi, 1989, Menjaga Mutu Pelayanan Rumah Sakit, PT. Citra Windu Satria, Jakarta.

2004, Keputusan Menteri Pemberdayaan Aparatur Negara No: KEP/25/M.PAN/2/2004 tentang Pedoman Umum Penyusunan Indeks Kepuasan Masyarakat Unit Pelayanan Instansi Pemerintah, Kementrian Pemberdayagunaan Aparatur Negara, Republik Indonesia.

, 1993, Keputusan Menteri Pendayagunaan Aparatur Negara Nomor 81/KEP/M.PAN/1993 tentang, Pedoman Umum Penyelenggaraan Pelayanan Publik, Kementrian Pemberdayagunaan Aparatur Negara, Republik Indonesia.

Kotler, Philip .2003. Marketing Management. Prentice Hall. New Jersey

Kotler, Philip, 2002, Manajemen Pemasaran Jilid I dan 2 (Terjemahan Benjamin Molan), Prenhallindo, Jakarta.

Kotler, Philip, 2003, Manajemen Pemasaran, Edisi Millennium 1, (Terjemahan hendra teguh, Prenhallindo, Jakarta.

Parasuraman A, 1990, Analisa Kualitas Pelayanan, Ghalia, Indonesia

Payne, Andrian, 1993, Pemasaran Jasa, Jakarta.

Rangkuti, Freddy .2002. Riset Pemasaran. Jakarta: Gramedia Pustaka Ulama.

Santoso, Edi, 2005, Indeks Kepuasan Masyarakat Dari Pelayanan Dinas Pengairan Kabupaten Bondowoso Yang Diterima Oleh Penyedia Jasa Konstruksi, tesis, Magister Manajemen, Universitas Narotama, Surabaya.

Sugiono, 2005, Metode Penelitian Administrasi, Alpabeta, Bandung.

Sumarmi, Sri Edi, 2006, Pemberian Pelayanan Prima Untuk Meningkatkan Kepuasan Keluarga Pasien Di Rumah Sakit Jiwa Menur Surabaya, Universitas Narotama, Surabaya.

Suprapto, 1998, Pengukuran tingkat Kepuasan pelanggan untuk pangsa pasar, Rineka Cipta, Surabaya

,2010, Laporan Tahunan Rumah Sakit Budi Kemuliaan Batam, Rumah Sakit

Budi Kemuliaan Batam, Batam. 